\title{
Assessing epidemiological evidence for the teratogenic effects of anticonvulsant medications
}

\section{H Dolk, P McElhatton}

\section{Antiepileptic medication in pregnancy}

$E^{\mathrm{o}}$ pidemiological studies of pregnancy outcomes of women with epilepsy are important, primarily to inform choice of treatment options in clinical care of pregnant women and to inform counselling, the need for prenatal and postnatal screening, and the need for early medical, behavioural, or educational intervention

In this issue (page 251), Dean et al report on a long term follow up of the health and neurodevelopment of children exposed to antiepileptic drugs before birth. They did this by consulting obstetric records to identify mothers with epilepsy who delivered in a single maternity unit between 1976 and 2000, inviting mothers to participate in the study by letter via their primary care physicians, conducting an interview with participant mothers, and consulting a variety of medical and child health records. The oldest children in the study were 15 years of age.

There is a fairly solid consensus that epilepsy in pregnancy treated with anticonvulsants is associated with an overall two- to three-fold increased risk of congenital malformation compared to the general population. The first challenge of the epidemiological approach is to mount sufficiently large studies. Since epilepsy is fortunately uncommon (6 per 1000 pregnancies or less), and since major congenital malformations are uncommon (2-3\% of all births), every 10000 pregnancies will yield only three or four cases of major congenital malformation born to epileptic women. Kallen, ${ }^{1}$ reviewing the results of 24 studies, indicated that nearly half of these studies included fewer than 150 infants born to epileptic mothers and did not have the statistical power to reveal a twoto three-fold raised risk of major malformation. It is generally necessary therefore to make a combined assessment of existing studies, particularly when assessing risks of specific anomalies. Schardein ${ }^{2}$ reviewed 17 cohort studies including a total of 2168 infants of women receiving anticonvulsant treatment to calculate absolute risks of $1.8 \%$ for congenital heart disease and $1.7 \%$ for facial clefts, the two types of congenital anomaly most commonly associated with maternal epilepsy. Similarly, very large studies or pooling of studies are needed to investigate differences in risk between different types of drug. The study of Dean et al makes a further contribution to the pool of available data on the risk of specific anomalies and their association with specific drugs.

A smaller body of research has tackled the longer term neurodevelopmental outcome of exposed children, these studies having the added problem of achieving follow up of the cohort of children identified and obtaining more complex neurodevelopmental data. In the study of Dean et al, of 411 women identified from obstetric records as having epilepsy, one quarter had moved away and were therefore not available for follow up, and two fifths of those still in the area did not participate in the study, leaving 149 participants. This rather low follow up rate reduced the statistical power of the study and also raised the question of bias: were those who moved away or who did not participate more or less likely to have experienced adverse pregnancy outcomes than the participants? Developmental delay was defined as having any one or more of a need for speech therapy in child health records, not sitting by 10 months, not walking by 18 months, or special educational needs at school. This record based assessment contrasts with the methodology available to prospective cohort studies, where standardised neurodevelopmental assessments can be made. For example, Gaily et $a l^{3}$ assessed their exposed and control children at the age of 5 years with standardised psychological and neurodevelopmental evaluations, and Wide et $a l^{4}$ applied a standard developmental test to 9 month old infants. Such studies also have the opportunity to carry out testing blind to the disease or treatment status of the mother.

Why do some epidemiological studies find evidence of an increased risk of developmental delay or malformations and others not? The most superficial reason is alluded to above, that some studies simply lack statistical power to find differences in risk between the exposed cohort and the comparison group, particularly for rarer/newer drugs or rarer health outcomes. In addition, owing to the very wide range of drugs and outcomes studied, multiple statistical testing will throw up a certain number of "false positive" results where the difference between exposed and unexposed groups is simply the result of chance. At the usual significance level of $5 \%$, for example, $5 \%$ of comparisons will find a statistically significant difference where there is no true underlying difference in risk. Differences in outcome between different drugs can similarly be chance differences. Thus, for example, Dean et al's finding that developmental delay is associated with all the major drug types but not phenobarbitone should be interpreted with caution until assessed for its consistency with other studies.

There are also more informative reasons why results of studies may conflict, relating to study design. Since studies are observational rather than experimental, they are open to various sources of bias. Bias can result from selection of a comparison group which differs from the cohort of epileptic women in other respects than disease or treatment status. For example, one study found epileptic mothers to be younger at delivery of their children and more likely to be of lower social class 5 than the population of the same region, emphasising the need to control or match for these characteristics. Bias may also result from differing levels of and reasons for non-participation in the exposed and comparison group. Apparently conflicting study results can arise through differences in the measures of developmental delay (see above), behavioural disorder, fetal anticonvulsant syndrome, ${ }^{67}$ or minor anomalies. ${ }^{47}$ Studies may differ in how conditions are grouped together for analysis or inclusion criteria for study and control children, such as restricting study to children with normal intelligence ${ }^{3}$ or to cases without family history. Where the general population is used as a comparison, it can be difficult to find truly comparable statistics. For example, population studies of congenital malformation prevalence may ascertain cases of malformation more or less completely than a study of a cohort of epileptic women, especially with regard to anomalies diagnosed after the neonatal period. Ten of the 36 children with major malformations in the study of Dean et al had an inguinal hernia, a condition which is on the exclusion list for many congenital anomaly registers and therefore does not appear in general statistics. ${ }^{8}$ Population statistics concerning later developmental outcomes tend not to be available or are based on poorly standardised assessments. Thus, true differences can be 
masked and false differences observed Dean et al chose not to compare their findings with a cohort of non-epileptic women or the general population, but to identify a cohort of untreated epileptic women as the comparison group.

Finally, results of studies may differ because of true differences between the populations of the study. Women with epilepsy in different populations may differ with regard to the proportion following optimal treatment regimens or in genetic susceptibility to drug effects. ${ }^{9}$ If the study is not truly population based, there may be a tendency to enter into the study only women with severe epilepsy who attend particular types of clinic.

In the treatment of the pregnant epileptic woman, the potential harm to both mother and fetus of the epilepsy itself must be weighed against the potential harm of the drug treatments. Maternal epilepsy may affect fetal and child health through the effects of seizures during pregnancy, or through the genetic background associated with epilepsy, or through differences in maternal behaviour or family circumstance, pre- or postnatally. One problem in studies which set out to distinguish between the effects of the drugs and of the epilepsy itself is that few epileptic women do not have treatment and these women usually differ from those receiving treatment in other ways, including the characteristics of their epilepsy. In the study of Dean et al, for example, the non-exposed comparison cohort were taken to be 38 sibs of exposed cases who were not themselves exposed in utero, either because they were born before epilepsy developed or because the mother took no treatment. Apart from being unrepresentative, this comparison group is also very small, reducing the statistical power of the study to find differences between the exposed and unexposed cohort. The average age of the unexposed children was higher than that of children exposed to most drug treatments, posing potential problems in assuring that comparable medical and neurodevelopmental information was available throughout the study period.

To distinguish drug effects from disease effects, there are two main epidemiological arguments, as discussed by Dean et al. The first is to look for specificity of individual drug malformation associations, that is, if a type of malformation is associated with only one type of drug, it is more likely to be a drug than a disease effect. For example, a specific association between spina bifida and valproic acid and perhaps carbamazepine is suggested by some published reports. ${ }^{10}{ }^{11}$ However, specific indications for different drugs may confound this assessment of specificity. For example, phenytoin has been used for more severe epilepsy. The second argument is to look for a relationship between risk of adverse pregnancy outcome and dose or monoversus polytherapy, again an indicator of the drug itself as causal agent, although the severity of the epilepsy may again confound this association. A fairly consistent finding, supported by the results of Dean et al, is that the risk of polytherapy is greater than monotherapy, and this has led to current guidelines advising monotherapy during pregnancy. International or multicentric studies can be a useful tool to try to dissociate drug and disease, because of the wide variations existing in treatment practice. ${ }^{12}{ }^{13}$ Studies over long time periods can also track changes in treatment independently of epilepsy. ${ }^{14}$ The study of Dean et al covered a 15 year time period, differences in mean age of offspring of different drug treatments reflecting changes in drug treatment, also probably tending to dissociate drug and disease characteristics. On the other hand, the overall results relate to drug regimens that are in part no longer current, for example, phenobarbitone and phenytoin are now used less frequently.

A third way of distinguishing drug from disease effects is to introduce a further comparison group, those who receive antiepileptics for conditions other than epilepsy. ${ }^{75}$ Finally, studies of children of fathers with epilepsy can shed light on the importance of the genetic background in causing an excess risk of malformations. ${ }^{1}$

It is perhaps surprising that there is not more information available to evaluate accurately the health risks of maternal epilepsy and antiepileptic treatment for the fetus and child. In the study of Dean et al, nearly one third of the exposed cohort of children had either a major malformation or developmental delay, emphasising the importance of the problem. Further research with follow ups into childhood is clearly needed. It could even be argued that collecting basic information on long term outcome should be part of clinical care. The way forward should involve multicentric studies of large numbers of exposed pregnancies, with suitable control groups of unexposed (non-epileptic and epileptic non-treated) pregnancies, standardised assessments of outcome, and detailed information regarding seizure history and drug treatment. Single centre studies should design and report on their studies with a view to the need for meta-analysis or combined assessment of results across studies. Furthermore, as Dean et al conclude, it is likely that future research will want to focus on why, while the majority of children of epileptic women on antiepileptic drugs experience "normal" health and development, some experience significant problems, and thus how we can predict more precisely those at risk and target therapies more effectively. ${ }^{9}$
While further research is clearly needed, there is also evidence that existing knowledge is not being effectively incorporated into health care in all communities. ${ }^{16}$ In the UK, national guidelines are needed for treatment of epilepsy in women of child bearing age. These should address a range of issues, including whose responsibility it is to speak to teenagers/young women about potential problems should they become pregnant.

J Med Genet 2002;39:243-244

\section{Authors' affiliations}

H Dolk, Department of Epidemiology and Health Services Research, Faculty of Life and Health Sciences, University of Ulster, Shore Road, Newtownabbey BT37 OQB, UK

P McElhatton, National Teratology Information Service (NTIS), Regional Drug and Therapeutics Centre, Wolfson Unit, Claremont Place, Newcastle upon Tyne NE2 4HH, UK

Correspondence to: Professor H Dolk, Department of Epidemiology and Health Services Research, Faculty of Life and Health Sciences, University of Ulster, Shore Road, Newtownabbey BT37 OQB, UK;

h.dolk@ulst.ac.uk

\section{REFERENCES}

1 Kallen B. Epidemiology of human reproduction. London: CRC Press, 1988:133-9.

2 Schardein JL. Chemically induced birth defects. 3rd ed. New York: Marcel Dekker, 2000: 179-236.

3 Gaily E, Kantola-Sorsa E, Granstrom ML. Specific cognitive dysfunction in children with epileptic mothers. Dev Med Child Neurol 1990;32:403-14.

4 Wide K, Winbladh B, Tomson T, Sars-Zimmer K, Berggren E. Psychomotor development and minor anomalies in children exposed to antiepileptic drugs in utero: a prospective population-based study. Dev Med Child Neurol 2000;42:87-92

5 Fedrick J. Epilepsy and pregnancy: a report from the Oxford Record Linkage Study. BM 1973;2:442-8

6 Dean JCS, Moore SJ, Turnpenny PD. Developing diagnostic criteria for the fetal anticonvulsant syndromes. Seizure 2000;9:233-4.

7 Holmes LB, Harvey EA, Coull BA, Huntington KB, Khoshbin S, Hayes AM, Ryan LM. The teratogenicity of anticonvulsant drugs. N Engl J Med 2001;344: 1 132-8.

8 EUROCAT Working Group. EUROCAT report 7. Surveillance of congenital anomalies in Europe 1980-1994. Brussels: Scientific Institute of Public Health, 1997.

9 Finnell RH, Burn J. Effect of anti-epileptic drugs on intrauterine growth. Lancet 2000;356: 1537-8

10 Robert E, Rosa FW. Maternal valproic acid and congenital neural tube defects. Lancet 1982; ii:937.

11 Rosa FW. Spina bifida in infants of women treated with carbamazepine during pregnancy. N Engl J Med 1991;324:674-7.

12 Bertollini R, Kallen B, Mastrioacovo P, Robert $\mathrm{E}$. Anticonvulsant drugs in monotherapy: effects on the fetus. Eur J Epidemiol 1987; 3: 164-9

13 Kaneko S, Battino D, Andermann E, Wada K, Kan R, Takeda A, Nakane Y, Ogawa Y, Avanzini G, Fumarola C, Granta T, Molteni F, Pardi G, Minotti L, Canger R, Dansky L, Oguni $M$, Lopes-Cendas I, Sherwin A, Andermann F Seni $M-H$, Okada M, Teranishi T. Congenital malformations due to antiepileptic drugs. Epilepsy Res 1999;33:145-58. 
14 Lindhout D, Meinardi $\mathrm{H}$, Meijer JWA, Nav $H$. Antiepileptic drugs and teratogenesis in two consecutive cohorts: changes in prescription policy paralleled by changes in pattern of malformations. Neurology 1992;42(suppl 5):94-110.
15 Nulman I, Scolnik D, Chitayat D, Farkas LD Koren $G$. Findings in children exposed in utero to phenytoin and carbamazepine monotherapy: independent effects of epilepsy and medications. Am J Med Genet 1997:68:18-24.
16 Fairgrieve SD, Jackson $M$, Jonas $P$, Walshaw D, White K, Montgomery TL, Burn J, Lynch SA. Population based prospective study of the care of women with epilepsy in pregnancy. BM 2000;321:674-5.

\section{The teratogenicity of anticonvulsant drugs: a progress report}

\section{B Holmes}

\section{Antiepileptic medication in pregnancy}

$\mathrm{E}$ xposure to anticonvulsant drugs during pregnancy is one of the most common potentially teratogenic exposures, occurring in 1 in $250(0.4 \%)$ of pregnancies in a recent study in Boston. The teratogenicity of these drugs was first postulated in the 1960s, with a consensus developing in the 1970s that a distinctive anticonvulsant embryopathy was produced. Two theories developed as to the cause: (1) the mother's underlying epilepsy $^{2}$ and (2) the anticonvulsant drug. ${ }^{3}$

All anticonvulsants marketed up to 1976 have been shown to be teratogenic, with varied manifestations and degrees of severity. Hopefully some of the "new" anticonvulsants marketed in the 1990s, for example, gabapentin (1993), lamotrigine (1994), and topiramate (1996), will be shown not to be teratogenic.

\section{PATTERNS OF EFFECTS}

I define a teratogenic effect as any harmful fetal effect from an exposure during pregnancy. Some effects are apparent at birth and others at older ages. The most common abnormalities identified in newborn infants are major malformations, midface and digit hypoplasia, microcephaly, and growth retardation. Experience has shown the importance of systematic evaluations ${ }^{4}$ for these outcomes, including definitions of the physical features being looked for, measurements, inclusion and exclusion criteria $^{5}$ for major malformations, and regular assessments of the reproducibility of the findings. ${ }^{67}$

\section{Major malformations}

Theoretically each anticonvulsant drug could produce specific or distinctive abnormalities; a few have been identified Five percent of valproic acid exposed infants in one large study ${ }^{8}$ and $1 \%$ of carbamazepine exposed infants ${ }^{9}$ had spina bifida; nothing distinctive about the spina bifida lesion has been reported and the frequency of other neural tube defects, such as anencephaly, is not increased Long bone and preaxial deficiencies in valproic acid exposed infants have been reported..$^{10}$ Stiff, tapered fingers with absent or very small nails in phenytoin exposed infants, in association with radiographic changes, for example, coned epiphyses and shortened and hypoplastic distal phalanges, have been found in phenytoin exposed infants. ${ }^{11}$ Vascular disruption limb anomalies, such as terminal transverse limb defects with nubbins, ${ }^{12}$ have been seen in occasional phenytoin exposed infants.

Since these associated major malformations are relatively uncommon, even in infants exposed to these specific drugs, the major malformations identified most often in anticonvulsant exposed children are those which also occur in unexposed children: heart defects, hypospadias, club foot, and cleft lip or palate. ${ }^{13-15}$

It is usually difficult to know if an infant's major malformation is "the result of" the fact that his/her mother had taken an anticonvulsant drug during pregnancy. Theoretically, this could be presumed if the infant has some of the other features of the anticonvulsant embryopathy, such as the infant with holoprosencephaly who had the minor craniofacial and digit anomalies of the phenytoin embryopathy. ${ }^{16}$ In one analysis, ${ }^{17}$ the infants with a drug specific feature, such as the "anticonvulsant face" or midface hypoplasia, were more likely to have the other features of the embryopathy than control infants.

Microcephaly and growth retardation Initial reports of children with the hydantoin, ${ }^{3}$ carbamazepine, ${ }^{18}$ and phenobarbital embryopathy ${ }^{19}$ proposed that microcephaly and growth retardation were fetal effects of these exposures. But this outcome could have reflected the effect of polytherapy in some of the children evaluated. More recent studies of infants exposed to phenytoin, carbamazepine, and phenobarbital as monotherapy did not identify an increased frequency of microcephaly. ${ }^{2021}$ An appropriate comparison group by race and altitude ${ }^{22}$ is crucial to these analyses.

\section{Midface hypoplasia}

The most common features are depressed bridge of the nose, short nose with anteverted nostrils, and long upper lip. Less common features are a broad bridge of the nose, thin vermilion, a small mouth, and a wide philtrum. ${ }^{23}$

Cephalometric radiographs of children who had been exposed to either phenytoin alone or phenytoin plus phenobarbital have shown significant changes in the facial bones and the cranial base: decreased length and height of the maxilla, decreased length of the posterior cranial base and mandible, altered maxillomandibular relationship, and shortened nasal bone. ${ }^{24}$ These changes persist beyond childhood.

Because two other teratogens, thalidomide and tetracycline, affect the teeth of children exposed in utero, the size and shape of the teeth in panoramic radiographs and dental casts from children exposed to either phenytoin alone or phenytoin and phenobarbital as polytherapy were analysed. ${ }^{25}$ An increased frequency of missing teeth and an increase in the mesiodistal diameter, particularly in the maxillary molars, was found. It will be important to determine whether other anticonvulsants produce similar changes in cranial structures and teeth.

\section{Digit hypoplasia}

An increased frequency of arch patterns and shortening of the distal phalanges has been reported in several studies. ${ }^{26-28}$ Changes in the frequency of other dermal ridge patterns also occur, but are less common. ${ }^{29}$ The higher frequency of arch patterns could reflect the fact that the prenatal exposures made the developing pad on the ends of the fingers lower than the pads associated with developing whorl and loop patterns. ${ }^{30}$

Hand radiographs of anticonvulsant exposed children show hypoplastic or malformed distal phalanges, coned epiphyses, pseudoepiphyses, and shortened metacarpals. ${ }^{11}$ In a study of 46 children between the ages of 5 and 29 years, 14\% of the phenytoin and/or phenobarbital 
exposed subjects had at least two of these changes. ${ }^{11}$ Since the measured nail sizes of these children in this study were not reduced, it was concluded that the presence of digit hypoplasia was determined most consistently from examining dermal ridge patterns and radiographs, not clinical inspection. The radiographs of the toes of the same subjects did not show a significant increase in the frequency of epiphyseal changes. ${ }^{31}$

\section{Cognitive function}

Assessments of intelligence have been the most common studies reported in older anticonvulsant exposed children and teenagers, ${ }^{3181932-35}$ some of whom have shown evidence of cognitive dysfunction.

\section{Phenobarbital}

The evaluation of 33 adult men showed a deficit of 7 IQ points ${ }^{32}$ with confounding by socioeconomic factors and a dose response relationship; another study $y^{33}$ of 23 matched pairs aged 6.5 to 16 years showed a difference of 11 full scale IQ points, with the phenobarbital exposed also having specific problems with either language expression or reception.

\section{Phenytoin}

The study ${ }^{34}$ of 34 mother-child pairs showed a $10.6( \pm 27.9)$ IQ point difference in 2 to 3 year olds compared to 34 matched pairs. Adams et $a l^{33}$ evaluated 21 phenytoin exposed children aged 6.5 years and older in comparison to matched controls and found no difference in comparison to 21 matched controls.

Phenytoin and phenobarbital A study ${ }^{35}$ of 15 drug exposed children showed, in comparison to controls, a deficit of 10 IQ points in both the Wechsler Full Scale IQ and the Performance IQ at 4.5 years and older.

\section{Carbamazepine}

Thirty-six mother-child pairs showed no difference at ages 2 to 3 years between those exposed to carbamazepine and the 33 mother-child pairs in the comparison group. $^{34}$

Based on the information published so far, the greatest concern about cognitive dysfunction is for children exposed in utero to valproic acid. Since the reports have come from case series ${ }^{36}$ and not systematic, controlled studies, it is difficult to know how frequent developmental delay and mental retardation are in valproate exposed children. An additional concern is the occurrence of autism in case reports of children exposed to valproic acid during pregnancy $^{38}{ }^{39}$; a systematic study of this very serious potential fetal effect is needed.

While these small systematic studies and case series show that cognitive dysfunction can be an effect of prenatal exposure to anticonvulsants, the limitations of the studies cited above illustrate the major issues and potential confounding factors to be considered: the test instruments and subtests used; the sample size should have adequate statistical power; the comparison group should be well matched; the evaluators should be masked as to exposure status; the age of the children being evaluated, children aged 6 years and older have a larger repertoire of knowledge to be tested and the findings should be more consistent than those in 2 and 3 year-olds; the intelligence of the parents of the exposed and comparison child should be assessed and considered in the analysis; the mother's history of epilepsy posing a "genetic" risk to each of her infants; the seizures which the mother had during the child's pregnancy; the presence of the features of the anticonvulsant embryopathy in the drug exposed child and the comparison child.

Hopefully future studies will include as many of these confounders as possible with the detailed analysis of the children and their parents.

The fetal effect of each potential confounding factor could theoretically be evaluated in separate studies. This has been done for the potential "genetic" risk to the fetus from the mother's history of epilepsy in a pregnancy when she was not taking an anticonvulsant drug and did not have seizures severe enough to make her unconscious. ${ }^{40}$ In this study, 57 seizure history (no drug) exposed children had no dysmorphic features and their intelligence was the same as that of the 57 matched controls. The power of the study was adequate to rule out a difference of 7 IQ points.

\section{Late onset effects}

An exposure during pregnancy can also produce fetal effects that are only apparent when that person is a teenager or young adult. Two examples from studies of other teratogens are the altered social behaviour in adult men who had been exposed in utero to diethylstilbestrol ${ }^{41}$ and the higher frequency of diabetes mellitus in adults with congenital rubella. ${ }^{42}$

Recently, Dessens et al ${ }^{43}$ reported an increased frequency of cryptorchidism in males exposed to phenytoin and/or phenobarbital during pregnancy and, later, menstrual irregularities in adult women. Dean et al report on page 251 of this issue of JMG the findings in a retrospective review of the medical records of 293 anticonvulsant exposed children. They identified an increased frequency of developmental delay, behaviour disorders, and a diverse group of medical problems that included refractive errors in vision, joint laxity, and otitis media (only in valproate exposed children).

\section{Genetic susceptibility}

Twenty years ago, David Smith ${ }^{44}$ presented his clinical observation that parents with one child with phenytoin embryopathy had a higher risk of having a second affected child than the parents whose anticonvulsant exposed fetus showed no signs of the embryopathy in childhood. Both Van Dyke et $a l^{45}$ and Moore et $a b^{37}$ confirmed the increased recurrence risk after the birth of an infant with the anticonvulsant embryopathy.

Several hypotheses have been developed to explain why some infants of mothers taking anticonvulsant drugs have this apparent genetic susceptibility: (1) decreased function of epoxide hydrolase (EPHXI), an enzyme which metabolises phenytoin, postulated to be the result of an autosomal recessive gene in one study ${ }^{46}$ and an autosomal dominant mutation in another ${ }^{47} ;(2)$ altered distribution of polymorphisms in microsomal EPHXI, no abnormalities were identified in one study of 16 subjects with the anticonvulsant embryopathy (L Walsh, J K Hartsfield Jr, personal communication); (3) production of free radicals by phenytoin $^{48}$; (4) inhibition of potassium channel function ${ }^{49}$, which produces injury by hypoxia and reperfusion; (5) decreased maternal serum folate, possibly associated with a deficiency of methylene tetrahydrofolate reductase. ${ }^{50}$

\section{Counselling the pregnant woman taking an anticonvulsant}

Because exposure to anticonvulsants is so common among pregnant women, it is important that all health care professionals be able to inform her of the potential for fetal effects and her options in her treatment, which include: take a daily folic acid supplement before conception; take the anticonvulsant drug as monotherapy, if possible; keep the dose of the anticonvulsant drug during pregnancy as low as possible, as the lower the dose presumably the lower the risk of a harmful fetal effect. Describe the increased risk for the spectrum of common malformations; do not emphasise an increased risk for cleft lip and palate, as this has been notable only for phenobarbital with an odds ratio of about $3 .{ }^{15}$ Even when the mother takes phenobarbital, that risk should be put in the context of the rate in that mother's ethnic group: if she is white, the baseline risk is about $1: 1000$ or $0.1 \%$ and a three-fold increase makes the risk $1: 333$ or $0.3 \%$. This de-emphasis would help make her concerns more realistic.

\section{Future directions}

This review highlights the need for more information on many aspects of the teratogenicity of anticonvulsants. First, hopefully the "new" anticonvulsants will be shown not to be teratogenic. Second, determine whether taking folic acid conception reduces the risks for a harmful 
fetal effect. Third, do anticonvulsant exposed children have an increased risk for cognitive dysfunction? Fourth, the "anticonvulsant face" is a common effect; is its presence associated with an increased risk for cognitive dysfunction? Fifth, studies are needed to identify the candidate genes that are associated with the familial clustering of children with the anticonvulsant embryopathy. One would predict that each drug will have its own molecular mechanism for conveying this risk. Hopefully, it will be possible to identify the woman with a high risk for a teratogenic effect from taking one anticonvulsant drug and to select a lower risk treatment for her.

\section{ACKNOWLEDGEMENTS}

Much of the work summarised has been supported by NIH Grant No NS24125, and funds from Parke-Davis (now Pfizer) and the Peabody Foundation. I also thank Mrs Rosanna Greco who typed this manuscript.

J Med Genet 2002;39:245-247

\section{Author's affiliation}

L B Holmes, Genetics and Teratology Unit, Pediatric Service, Massachusetts General Hospital, Warren 801, 55 Fruit Street, Boston, MA 021 14-2696, USA

Correspondence to: Dr L B Holmes;

holmes.lewis@mgh.harvard.edu

\section{REFERENCES}

1 Holmes LB, Harvey EA, Coull BA, Huntington KB, Khoshbin S, Hayes AM, Ryan LM. The teratogenicity of anticonvulsant drugs. $N$ Engl J Med 2001;344: $1132-8$.

2 Monson RR, Rosenberg L, Hartz SC, Shapiro S, Heinonen OP, Slone D. Diphenylhydantoin and selected congenital malformations. $N$ Engl J Med 1973;289:1049-52.

3 Hanson JW, Myrianthopoulos NC, Harvey MA, Smith DW. Risks to the offspring of women treated with hydantoin anticonvulsants, with emphasis on the fetal hydantoin syndrome. J Pediatr 1976;89:662-8.

4 Leppig KA, Werler MM, Cann Cl, Cook CA, Holmes LB. Predictive value of minor anomalies. I. Association with major malformations. J Pediatr 1987; 1 10:53 1-7.

5 Holmes LB. Need for inclusion and exclusion criteria for the structural abnormalities recorded in children born from exposed pregnancies. Teratology 1999;59:1-2.

6 Holmes LB, Kleiner BC, Leppig KA, Cann Cl, Munoz A, Polk BF. The predictive value of minor anomalies. II. Use in cohort studies to identify teratogens. Teratology 1987; $36: 291-7$

7 Harvey EA, Hayes AM, Holmes LB. Lessons on objectivity in clinical studies. Am J Med Genet 1994:53:19-20

8 Omtzigt JG, Los FJ, Grobbee DE, Pijpers L, Jahoda MGJ, Brandenburg $\mathrm{H}$, Stewart PA, Gaillard HL, Sachs ES, Wladimiroff JW, Lindhout $D$. The risk of spina bifida aperta after first-trimester exposure to valproate in a prenatal cohort. Neurology 1992;42:119-25.

9 Rosa FW. Spina bifida in infants of women treated with carbamazepine during pregnancy. N Engl J Med 1991;324:674-7

10 Sharony R, Garber A, Viskochil D. Preaxial ray reduction defects as part of valproic acid embryopathy. Prenat Diagn 1993;13:909-18.
11 Lu MCK, Sammel MD, Ryan LM, Holmes LB. Digit effects produced by prenatal exposure to antiepileptic drugs. Teratology 2000;61:277-283.

12 Sabry MA, Farag TI. Hand anomalies in fetal-hydantoin syndrome: from nail/phalangeal hypoplasia to unilateral acheiria. Am J Med Genet 1996;62:410-12.

13 Battino D, Binelli S, Caccamo ML, Canevin $M P$, Canger R, Como ML, Croci D, De Giambattista M, Granata T, Pardi G, van Avanzini G. Malformations in offspring of 305 epileptic women: a prospective study Acta Neurol Scand 1992;85:204-7.

14 Samren EB, van Duijn CM, Koch S, Hiilesmaa VK, Klepel H, Bardy AH, Mannagetta GB, Deichl AW, Gaily E, Granstrom ML, Meinardi H, Grobbee DE, Hofman A, Janz D, Lindhout D. Maternal use of antiepileptic drugs and the risk of major congenital malformations: a joint European prospective study of human teratogenesis associated with maternal epilepsy. Epilepsia 1997;38:981-90.

15 Arpino C, Brescianini S, Robert E, Castilla EE, Cocchi G, Cornel MC, de Vigan C, Lancaster PA, Merlob P, Sumiyoshi Y, Zampino G, Renzi C, Rosano A, Mastroiacovo P. Teratogenic effects of antiepileptic drugs: use of an International Database on Malformations and Drug Exposure (MADRE). Epilepsia 2000;41:1436-43.

16 Kotzot D, Weigl J, Huk W, Rott HD. Hydantoin syndrome with holoprosencephaly: a possible rare teratogenic effect. Teratology 1993;48:15-19.

17 Holmes LB, Coull BA, Harvey EA, Hayes AM. Major malformations in anticonvulsant-exposed children: association or coincidence? (Spanish). Boletin del ECEMC 2001; Serie IV(No 6):31-4.

18 Jones KL, Lacro RV, Johnson KA, Adams J. Pattern of malformations in the children of women treated with carbamazepine during pregnancy. N Engl J Med 1989;320:1661-6.

19 Jones LL, Johnson KA, Chambers CC. Pregnancy outcome in women treated with phenobarbital monotherapy. Teratology 1992:45:452.

20 Nulman I, Scolnik D, Chitayat D, Farkas LD Koren $G$. Findings in children exposed in utero to phenytoin and carbamazepine monotherapy; independent effects of epilepsy and medications. Am J Med Genet 1997;68: 18-24

21 Choulika S, Harvey E, Holmes LB. Effect of antiepileptic drugs (AED) on fetal growth: assessment at birth. Teratology 1999;59:388.

22 Wong KS, Scott KE. Fetal growth at sea level. Biol Neonate 1972;20:175-88.

23 Orup HI Jr, Holmes LB. Changes in facial soft tissues in individuals exposed to antiepileptic drugs in utero. Teratology 1998;57:195-6.

24 Orup HI Jr, Holmes LB. Persistence of craniofacial effect of antiepileptic drug (AED) teratogenicity into adult years. Teratology 1997;55:34.

25 Orup HI Jr, Keith DA, Holmes LB. Prenatal anticonvulsant drug exposure: teratogenic effect on the dentition. J Craniofac Genet Dev Biol 1998;18:129-37.

26 Hanson JW, Smith DW. The fetal hydantoin syndrome. J'Pediatr 1975;87:285-90.

27 Kelly TE, Edwards P, Rein M, Miller JQ, Dreifuss FE. Teratogenicity of anticonvulsant drugs. II. A prospective study. Am J Med Genet 1984;19:435-43.

28 Andermann E, Dansky L, Andermann F, Loughman PM, Gibbons J. Minor congenital malformations and dermatoglyphic alterations in the offspring of epileptic women: a clinical investigation by the teratogenic effects of anticonvulsant medication. In: Janz D, Bossi L, Dam M, Helge H, Richens A, Schmidt D, eds. Epilepsia, pregnancy, and the child. New York: Raven Press, 1982:235-49.

29 Bokhari A, Coull B, Holmes LB. Effect of prenatal exposure to antiepileptic drugs on dermal ridge patterns of fingers. Teratology 1999;59:379.

30 Robinow M, Johnson GF. Dermatoglyphics in distal phalangeal hypoplasia. Am J Dis Child 1972;124:860-3
31 Bokhari A, Connolly S, Harvey EA, Holmes LB. Effects on toes produced by prenatal exposure to antiepileptic drugs (AED) are common, but subtle. Teratology 1998;57:55

32 Reinisch JM, Sanders SA, Rubin DB. In utero exposure to phenobarbital and intelligence deficits in adult men. JAMA 1995; 724:1518-25.

33 Adams J, Harvey EA, Holmes LB. Cognitive deficits following gestational monotherapy with phenobarbital and carbamazepine. Neurotoxicol Teratol 2000:22:466.

34 Scolnik D, Nulman I, Rovet J, Gladstone D Czuchta D, Gardner HA, Gladstone R, Ashby P, Weksberg R, Einarson T, Koren G. Neurodevelopment of children exposed in utero to phenytoin and carbamazepine monotherapy. JAMA 1994;271:767-70.

35 VanOverloop D, Schnell RR, Harvey EA, Holmes LB. The effects of prenatal exposure to phenytoin and other anticonvulsants on intellectual function at 4 to 8 years. Neurotoxicol Teratol 1992;14:329-35

36 Ardinger $\mathrm{HH}$, Atkin JF, Blackston RD, Elsas U, Clarren SK, Livingstone S, Flannery DB, Pellock JM, Harrod M, Lammer EJ, Majewski F, Schinzel A, Toriello HV Hanson JW. Verification of the fetal valproate syndrome phenotype. Am J Med Genet 1988;29:171-85.

37 Moore SJ, Turnpenny P, Quinn A, Glover S, Lloyd DJ, Montgomery T, Dean JC. A clinical study of 57 children with fetal anticonvulsant syndromes. J Med Genet 2000;37:489-97.

38 Christianson AL, Chester N, Kromberg JGR. Fetal valproate syndrome: clinical and neurodevelopmental features in two sibling pairs. Dev Med Child Neurol 1994;36:361-9.

39 Williams PG, Hersh JH. A male with fetal valproate syndrome and autism. Dev Med Child Neurol 1997;39:632-4

40 Holmes LB, Rosenberger PB, Harvey EA, Khoshbin S, Ryan L. Intelligence and physical features of children of women with epilepsy. Teratology 2000;61:196-202.

41 Beral V, Colwell L. Randomized trial of high doses of stilbestrol and ethisterone therapy during pregnancy: long-term follow-up of the children. J Epidemiol Community Health 1981;35:155-60.

42 Shaver KA, Boughman JA, Nance WE. Congenital rubella syndrome and diabetes: a review of epidemiologic, genetic and immunologic factors. Am Ann Deaf 1985;130:526-32.

43 Dessens AB, Cohen-Kettenis PT, Mellenbergh GJ, Koppe JG, Poll NE, Boer K. Association of prenatal phenobarbital and phenytoin exposure with genital anomalies and menstrual disorders. Teratology $2001 ; 64: 181-8$

44 Smith DW. Hydatoin effects on the fetus in phenytoin-induced teratology and gingival pathology. New York: Raven Press, 1980.

45 Van Dyke DC, Hodge SE, Helde F, Hill LR. Family studies in fetal phenytoin exposure. $J$ Pediatr 1988; 1 13:301-6.

46 Buehler BA, Delimont D, van Waes M, Finnell $\mathrm{RH}$. Prenatal prediction of risk of the fetal hydantoin syndrome. N Engl J Med 1990;322:1567-72.

47 Strickler SM, Dansky LV, Miller MA, Seni $\mathrm{MH}$, Andermann E, Spielberg SP. Genetic predisposition to phenytoin-induced birth defects. Lancet 1985;ii:746-9.

48 Wells PG, Nagri MK, Grego GS. Inhibition of trimethadione and dimethadione teratogenicity by the cyclooxygenase inhibito acetylsalicylic acid: a unifying hypothesis for the teratogenic effects of hydantoin anticonvulsants and structurally related compounds. Toxicol Appl Pharmacol 1989;97:406-14

49 Danielsson BRG, Danielson M, Rundqvist $E$, Rieland S. Identical phalangeal defects induced by phenytoin and nifidipine suggest hypoxia and vascular disruption behind phenytoin teratogenicity. Teratology 1992;45:247-58

50 Dean JCS, Moore SJ, Osborne A, Howe J, Turnpenny PD. Fetal anticonvulsant syndrome and mutation in the maternal MTHFR gene. Clin Genet 1999;56:216-20. 
maternal antiepileptics, a two- to threefold greater risk than in unexposed children. ${ }^{11-14}$ Specific patterns occur, with

\section{Antiepileptic drug therapy during pregnancy: the neurologist's perspective}

\section{S Shorvon}

\section{Antiepileptic medication in pregnancy}

E pilepsy causes disadvantage for many reasons, and for women there are particular problems associated with epilepsy in pregnancy. Some are the direct result of seizures, some result from the drug treatment, and some are secondary handicaps because of stigmatisation. It was not very many generations ago that women with epilepsy were routinely advised not to reproduce, and in many countries, even in recent times, there have been legal interdictions on marriage and childbearing. In the western democracies, less prejudicial attitudes now prevail, but recent epidemiological evidence still shows that women with epilepsy, when compared to controls, have lower fertility rates, ${ }^{1}$ children born later, lower rates of marriage, ${ }^{2}$ higher rates of sexual dysfunction, ${ }^{3}$ and hormonal changes. ${ }^{4}$ There are currently about 75000 women of childbearing age on treatment for epilepsy in the UK, ${ }^{1}$ and about $0.3-0.4 \%$ of all births are to mothers with epilepsy. The neurologist has a duty to provide information and advice on many issues relating to the management of epilepsy in pregnancy, an increasing imperative as these issues have become the focus of much public interest. A key to all decision making is that the women should be fully involved and informed about the choices, and decisions made after full discussion.

Ideally the issues relating to epilepsy and pregnancy should be brought up well in advance of any planned pregnancy to allow informed and well considered choices. In preconceptional counselling, it is first necessary to decide whether treatment is indicated at all. This will depend on an assessment of the balance of risks of drug treatment versus those of the untreated epilepsy. A decision to withhold treatment might be made, for instance in some patients with minor seizures, reflex seizures, seizures at night, or infrequent seizures. Rules are not possible to formulate and decisions are highly individual.

The risk to the fetus of the antiepileptic drugs (the risk of teratogenicity) is of course a major concern, but understanding of this topic is evolving and this complicates the advice that can be given. The first conclusive report of anticonvulsant teratogenicity was a letter in The Lancet by Meadow, ${ }^{5}$ who reported hare lip and cleft palate and other abnormalities in six children whose mothers were taking phenytoin, barbiturate, and troxidone. Before this, there were no concerns about prescribing in epilepsy during pregnancy, and it is worth noting that phenobarbitone had been in use since 1912, phenytoin since 1938, and troxidone (a severe teratogen) since 1946. Other reports followed, and by the mid 1970s it was believed that the risk of fetal malformation in the infants of mothers taking antiepileptics was about twice that expected. ${ }^{67}$ Nevertheless, the orthodox advice was still generally that mothers should continue therapy (with folate supplementation) in view of the greater perceived risk of uncontrolled epilepsy. In 1975, the fetal hydantoin syndrome was first reported. ${ }^{8}$ At that time, the main prescribed antiepileptics were phenytoin, phenobarbitone, carbamazepine, and valproate, and the latter two drugs were increasingly recommended as first line drugs of choice in pregnancy. In 1981, valproate induced spina bifida was first reported, a risk estimated now to be about $1-2 \%$, ${ }^{9}$ and during the 1980s reports accumulated of this and other major malformations resulting from valproate. An editorial in the $B M J$ in 1985 , however, still placed valproate as the drug of choice for grand mal epilepsy in young women. A fetal valproate syndrome was first suggested in 1987, although its features and indeed its existence are still controversial. Spina bifida was noted to be associated with carbamazepine in 1990 (now thought to have a frequency of about $0.5-1 \%$ of exposed pregnancies), but during the 1990s most opinion concurred that this was the safest of the conventional drugs. Large studies were carried out in the 1990s, and a review in 1995 ranked the drugs for teratogenetic risk (in decreasing order: primidone, valproate, phenytoin, carbamazepine, and phenobarbitone). In recent studies, major malformations have been reported in between $6-9 \%$ of newborns exposed to valproate exposure associated with neural tube and skeletal defects, carbamazepine with neural tube and congenital heart defects, and phenytoin with congenital heart and digital defects and orofacial clefts. ${ }^{15}$ A range of newer drugs has been introduced to treat epilepsy in the last 10-15 years (including vigabatrin, lamotrigine, topiramate, tiagabine, and levetiracetam), but experience in pregnancy, even after 10 or more years of prescribing for some of these drugs, is slight and their teratogenetic potential is unclear. Some have proven teratogenicity in animals, and in view of the delay in recognition of the teratogenicity of previous drugs, there is a general, but not universal, reluctance to expose pregnant women to an essentially unknown risk.

The research emphasis until quite recently has been on the potential for antiepileptic drugs to cause major morphological anomalies. Growth retardation and minor morphological changes (for example, those comprising the socalled fetal syndromes of phenytoin, valproate, barbiturate, or benzodiazepines) are more controversial, and studies are confounded by genetic as well as other congenital factors, leading some to suggest that the various minor changes are in fact often not the result of medication. ${ }^{16}$ In the past few years, evidence has also been gathered suggesting that the antiepileptic drugs given in utero may result in intellectual disability and behavioural change in the offspring in later life. ${ }^{17-19}$ This is a worrying spectre, but conclusive proof is lacking to date. The article by Dean et al on page 251 of this issue adds to the concerns. Studies are of course difficult, and gold standard blinded and prospective investigations will take years to perform. If antiepileptic drugs, taken during pregnancy, do have a downstream effect on learning and behaviour, which is only manifest years after birth, the risk/benefit ratio of taking/not taking drugs during pregnancy will be altered. The frequency and severity of these effects is still essentially unknown, and predictive factors have not been identified. This makes neurological advice very difficult to give. The situation is complicated by the activities of some pharmaceutical companies, who since the mid 1990s, have been actively marketing drugs on the basis of their presumed safety or otherwise in pregnancy, making claims which have obscured rather than clarified rational decision making.

What advice about teratogenicity should be given to the women contemplating pregnancy now? The known risks of the major malformations should be discussed, and the potentially greater 
risks of relatively minor morphological changes. The possibility of later intellectual or behavioural difficulties should be raised, but it should be emphasised that currently the risk is unquantifiable. Some epilepsies are the result of genetic and heritable factors which may also be associated with intellectual delay, and the differentiation of drug versus genetic parental influences can be very difficult. Any counselling about risks of neurological defects in the offspring require an understanding of the maternal epilepsy syndrome. As the risk of teratogenicity is greatest with exposure in the first trimester (the time of greatest sensitivity is 3-4 weeks for neural tube defects, 4-8 weeks for congenital heart defects, and 6-10 weeks for orofacial clefts) and the risk of seizure related fetal injury greatest in the last trimester, one strategy is to initially withhold treatment and to start therapy in the second or third trimester. This course of action requires counselling and experience. If a women presents for advice regarding therapy having discovered that she is already pregnant, the drug influences causing major malformation may well have already applied. Altering therapy will therefore not reduce these risks. More subtle effects (for example, growth retardation, minor anomalies, cognitive effects), though, may develop later, and, again in spite of any conclusive evidence, it thus seems reasonable to reduce therapy where possible.

The women must weigh up the risks of drug therapy against those of seizure induced morbidity and mortality, both to her and the unborn fetus. Maternal morbidity includes the physical risks of accidents and the many psychosocial consequences of active epilepsy. Fetal morbidity in epilepsy is largely related to the mechanical risks of falling and of convulsions during the later stages of pregnancy, to the risks of seizures occurring during delivery, and to status epilepticus. Convulsions during delivery are a particular problem. These have resulted in maternal death and also in fetal asphyxia. ${ }^{20}$ One to two percent of women with epilepsy will have a convulsion during delivery, ${ }^{21}$ a risk presumably lowered by therapy. A case report of complex partial seizures during labour showed significant fetal heart rate decelerations and prolonged uterine contractions, ${ }^{23}$ and most seizures will also impair the mother's ability to cooperate during the delivery. These facts no doubt contribute to the greatly increased rate of caesarian section among epileptic women. Prolonged seizures, and in particularly status epilepticus, carry an undisputed risk. Teramo and Hiilesmaa, ${ }^{24}$ for instance, reported fetal death in about $50 \%$ of cases with status epilepticus during pregnancy and in $30 \%$ of the mothers. There is also some experimental evidence that seizures during pregnancy can have deleterious effects on the fetus, perhaps because of exposure to the short duration episodes of hypoxaemia or lactic acidosis which accompany severe seizures, although significant damage induced in this manner seems intuitively unlikely. Prospective studies have not shown an increased risk of birth defects in mothers who have seizures during pregnancy, although there are case reports of cognitive dysfunction in the offspring of women who have had convulsive as well as nonconvulsive seizures during pregnancy. ${ }^{17}$ Currently, most women with epilepsy are treated with antiepileptic drugs and the decision not to do so needs to be taken by a neurologist experienced in this area, and after full and frank discussion of the risks with the patient.

There are other points which should be part of the neurological management of epilepsy in pregnancy and prepregnancy counselling. Primary among these is the prescription of folic acid. Folate has been clearly shown to reduce the frequency of neural tube defects in the normal population. ${ }^{25}$ As some antiepileptic drugs (for example, phenytoin, phenobarbitone, and carbamazepine) reduce folate levels, and as neural tube defects are increased by therapy with some drugs (for example, valproate and carbamazepine), it seems sensible to ensure folate is taken by pregnant women with epilepsy, although it has to be admitted that few studies have been carried out to show beneficial effects in epilepsy. Folate should be given at higher doses (4 mg/day is often recommended) than in non-medicated women owing to the diminished absorption and increased metabolism of folate in patients on hepatic enzyme inducing antiepileptic drugs. Second is the question of monitoring and investigation. High quality ultrasound at 16-20 weeks of gestation has a high sensitivity and specificity in detection of major malformations, including more than $90 \%$ of neural tube defects, and a high proportion of cardiac malformations, skeletal defects, and orofacial clefts. If therapeutic termination is acceptable, this reduces very considerably the risks of offspring with malformations. Ultrasound at week 33-34 can also be useful in showing intrauterine growth retardation. Amniocenteses for amniotic fluid alpha-fetoprotein can be considered, but carries a $0.5-1.0 \%$ risk of precipitating abortion. Tailoring antiepileptic drug therapy can also be important. Where possible, single drug therapy should be used, as the risks of teratogenicity are clearly shown to be greater in polytherapy. It has widely been recognised since the 1980s that the more drugs that are used in combination, the greater are the risks. The dose of the chosen drug(s) should be minimised, as there is a clear relationship between dose of some drugs (for example, valproate) and teratogenic effect. The total dose of valproate (and possibly other drugs) should be divided and given three or four times a day to minimise high peak concentrations of the parent drug or its metabolites. The pharmacokinetics of most antiepileptic drugs change in pregnancy, and levels of phenytoin, phenobarbitone, and carbamazepine tend to fall, especially in later pregnancy. ${ }^{22} 2728$ The ratio of free/total serum levels of phenytoin alter in pregnancy and measurement of free levels is in some circumstances more reliable than that of total levels. Maternal ingestion of enzyme inducing antiepileptic drugs can result in low fetal vitamin $\mathrm{K}$ levels, and a consequential risk of perinatal haemorrhage owing to induced deficiencies of factors II, VII, IX, and X. Widely given advice, therefore, is to give oral vitamin $\mathrm{K}_{1}$ at a dose of $10-20 \mathrm{mg} /$ day to the mother in the last month of pregnancy and also $1 \mathrm{mg}$ intramuscularly to the infant at birth. ${ }^{29}{ }^{30}$ Counselling of the pregnant women (and the women contemplating pregnancy) should also include advice on the risk of epilepsy in the offspring, the increased risks of complications during pregnancy, ${ }^{31-33}$ the advisability of breast feeding, ${ }^{34-36}$ and precautions to be taken if maternal seizures are likely in relation to the care of the newborn. The commonest complaint of patients with epilepsy about hospital outpatient services, in the UK and elsewhere, is a perceived lack of information. ${ }^{39}$ This has been found to be particularly true for advice about pregnancy in epilepsy, and there is no area in epilepsy practice in which counselling and discussion are more important.

J Med Genet 2002;39:248-250

Author's affiliations

S Shorvon, Department of Clinical Neurology, Institute of Neurology, University College London, and National Neuroscience Institute, Singapore

Correspondence to: Professor S Shorvon, Institute of Neurology, National Hospital for Neurology and Neurosurgery, Queen Square, London WCIN 3BG, UK ;

sshorvon@singnet.com.sg

\section{REFERENCES}

1 Wallace H, Shorvon SD, Tallis R. Age-specific incidence and prevalence rates of treated epilepsy in an unselected population of $2,052,922$ and age specific fertility rates of women with epilepsy. Lancet 1998;352: 1970-4.

2 Callaghan N, Crowley M, Goggin T. Epilepsy and employment, marital, education and social status. Irish Med J 1992;85:17-19.

3 Demerdash A, Shaalan M, Midani A, Kamel $F$, Bahri M. Sexual behaviour of a sample of females with epilepsy. Epilepsia 1991;32:82-5

4 Duncan S. Polycystic ovarian syndrome in women with epilepsy: a review. Epilepsia 2001;42(suppl 3):60-5 
5 Meadow SR. Anticonvulsant drugs and congenital abnormalities. Lancet 1968;ii: 1296

6 Speidel BD, Meadow SR. Maternal epilepsy and abnormalities of the fetus and newborn. Lancet 1972;ii: $1196-7$.

7 Smithells RW. Teratogenic effects of anticonvulsants. Br Med Bull 1976;32:27-33.

8 Hanson JW, Smith DW. The fetal hydantoin syndrome. J Pediatr 1975:87:285-90.

9 Omtzigt JGC, Los FJ, Grobbee DE, Pijpers L, Jahoda MGJ, Brandenburg H, Stewart PA, Gaillard HL, Sachs ES, Wladimiroff JW, Lindhout D. The risk of spina bifida aperta after first-trimester exposure to valproate in prenatal cohort. Neurology 1992;42(suppl 5): 11 19-25.

10 Rosa FW. Spina bifida in infants of women treated with carbamazepine during pregnancy. N Engl J Med 1991;324:674-7.

11 Samrén B, van Duijn $C$, Koch S, Hiilesmaa VK, Klepel H, Bardy AH, Mannagetta GB, Deichl AW, Gaily F, Granstrom ML, Meinard $H$, Grobbee DE, Hofman A, Janz D, Lindhout D. Maternal use of antiepileptic drugs and the risk of major congenital malformations: a join European prospective study of human teratogenesis associated with maternal epilepsy. Epilepsia 1997:38:981-90.

12 Samrén B, van Duijn C, Christiaens GC, Hofman A, Lindhout D. Antiepileptic drug regimens and major congenital abnormalities in the offspring. Ann Neurol

1999:46:739-46.

13 Canger R, Battino D, Canevini MP, Fumarola C, Guidolin L, Vignoli A, Manoli D, Palmieri C, Molteni F, Granata T, Hassibi P, Zamperin F, Pardi G, Avenzini G. Malformations in offspring of women with epilepsy: a prospective study. Epilepsia 1999-40:1231-6.

14 Kaneko S, Battino D, Andermann E, Wada K, Kan R, Takeda A, Nakane Y, Ogawa Y Avanzini G, Fumarola C, Granata T, Molteni F, Pardi G, Minotti L, Canger R, Dansky L, Oguni M, Lopes-Cendes I, Sherwin A, Andermann F, Jeni MH, Okada M, Teranishi T. Congenital malformations due to antiepileptic drugs. Epilepsy Res 1999;33:145-58.
15 Holmes LB, Harvey EA, Coull BA, Huntington K, Khoshbin S, Hay A, Ryan L. The teratogenicity of anticonvulsant drugs. N Engl J Med 2001;344:1 132-8.

16 Gaily E. Minor anomalies and effects on psychomotor development associated with maternal use of antiepileptic drugs. In: Tomson T, Gram L, Sillanpää M, Johannessen SI, eds. Epilepsy and pregnancy. Petersfield: Wrightson Biomedical Publishing Ltd, 1997:63-70.

17 Gaily E, Kantola-Sorsa E, Granström ML. Specific cognitive dysfunction in children with epileptic mothers. Dev Med Child Neurol 1990;32:403-14

18 Reinisch JM, Sanders SA, Mortensen EL, Rubin DB. In utero exposure to phenobarbita and intelligence deficits in adult men. JAMA 1995; 274:1518-25.

19 Adab N, Jacoby A, Smith D, Chadwick D. Additional educational needs in children born to mothers with epilepsy. J Neurol Neurosurg Psychiatry 2001;70:15-21.

20 Teramo K, Hiilesmaa V, Bardy A, Saarikoski $S$. Fetal heart rate during a maternal grand mal epileptic seizure. J Perinat Med 1979;7:3-6

21 Bardy AH. Incidence of seizures during pregnancy, labor and puerperium in epileptic women: a prospective study. Acta Neurol Scand 1987;75:356-60.

22 Tomson T, Lindbom U, Ekqvist B, Sundqvist A. Epilepsy and pregnancy: a prospective study of seizure control in relation to free and total plasma concentrations of carbamazepine and phenytoin. Epilepsia 1994;35:122-30.

23 Nei M, Daly S, Liporace J. A maternal complex partial seizure in labor can affect fetal heart rate. Neurology 1998;51:904-6.

24 Teramo K, Hiilesmaa VK. Pregnancy and fetal complications in epileptic pregnancies. In: Janz D, Dam M, Richens A, Bossi L, Helge $H$, Schmidt D, eds. Epilepsy, pregnancy and the child. New York: Raven Press, 1982:53-9.

25 MRC Vitamin Study Research Group. Prevention of neural tube defects: results of the Medical Research Council Vitamin Study. Lancet 1991;338:131-7.
26 Czeizel AE, Dudas I. Prevention of the first occurrence of neural-tube defects by periconceptional vitamin supplementation. $N$ Engl J Med 1992;327: 1832-5.

27 Perucca E. Drug metabolism in pregnancy, infancy and childhood. Pharmacol Ther 1987;34:129-43.

28 Yerby MS. Friel PN. McCormick K. Antiepileptic drug disposition during pregnancy. Neurology 1992;42(suppl 5): 12-16.

29 Cornelissen M Steegers-Theunissen R, Kollee L, Eskes T, Motohara K, Monnens L. Supplementation of vitamin $\mathrm{K}$ in pregnan women receiving anticonvulsant therapy prevents neonatal vitamin K deficiency. Am J Obstet Gynecol 1993;168:884-8.

30 Hey $\mathbf{E}$. Effect of maternal anticonvulsant treatment on neonatal blood coagulation. Arch Dis Child 1999;81:F208-10.

31 Hiilesmaa VK, Bardy A, Teramo K. Obstetric outcome in women with epilepsy. Am J Obstet Gynecol 1985;152:499-504

32 Yerby $\mathbf{M}$, Koepsell T, Daling J. Pregnancy complications and outcomes in a cohort of women with epilepsy. Epilepsia 1985;26:631-5

33 Sabers A. Complications during pregnancy and delivery. In: Tomson T, Gram L, Sillanpää M, Johannessen SI, eds. Epilepsy and pregnancy. Petersfield: Wrightson Biomedical Publishing Ltd, 1997:105-111.

34 Vinge E. Breast-feeding and antiepileptic drugs. In: Tomson T, Gram L, Sillanpää $M$ Johannessen SI, eds. Epilepsy and pregnancy. Petersfield: Wrightson Biomedical Publishing Ltd, 1997:93-103.

35 Morrell MJ. Guidelines for the care of women with epilepsy. Neurology 1998;51/suppl 4): $521-7$.

36 Hägg S, Spigset $O$. Anticonvulsant use during lactation. Drug Safety 2000;22:425-40.

37 Poole K, Moran N, Bell GJ, Solomon JK, Kendall S, McCarthy M, McCormick D Nashef L, Johnson AV, Sander JW, Shorvon SD. Patients' perspectives on services for epilepsy: a survey of patient satisfaction, preferences and information provision in 2394 people with epilepsy. Seizure 2000:9:551-8. 